\section{Postdoctoral training: Time for change}

\section{The increasingly pressing problems facing postdoctor- al fellows in recent years call for a re-evaluation of the position of postdocs in academia and collaboration of involved parties to bring about positive change.}

Postdoctoral training is traditionally viewed as a step toward academic independence that allows $\mathrm{PhD}$ graduates to develop their research ideas and hone their scientific skills under the guidance of a primary investigator. But what used to be a short 'apprenticeship' that paved the route to scientific autonomy is now a state of limbo for many postdocs.

Nowadays, postdoctoral placements can stretch to upwards of 4-5 years, during which postdocs conduct research, help PIs secure grants and train graduate students and technical staff. The prevailing publish-orperish mentality and the limited length of postdoctoral funding, usually for 2-3 years, lead many postdocs to pursue consecutive placements. However, rather than improving employment prospects, lengthy postdoctoral experience can often impede a candidate's competitiveness on the academic job market by hampering eligibility for prestigious funding opportunities, which target candidates with relatively shorter intervals between gaining a $\mathrm{PhD}$ and pursuing a PI position.

More recently, the effort of many countries to boost their scientific output has increased the numbers of $\mathrm{PhD}$ graduates. As academia remains the top career choice for $\mathrm{PhD}$ graduates (see the US National Scientific Foundation survey on 'Doctorate recipients from United States universities: 2009'), the number of postdoctoral fellows in traditional strongholds of research has also risen, with biological science postdocs increasing by $23 \%$ in the USA between 1999-2008. In contrast long-term academic job prospects have not only failed to improve, but the scarcity of PI positions has been exacerbated by the current global economic crisis that resulted in hiring freezes across research institutes and shrinking science budgets in many countries.

The poorly defined professional status of postdocs, especially in the US where they are usually not classed as staff, often translates to inequalities between postdoctoral programmes. Disparities are common in financial terms, as funding fellowships can be awarded by the host institute or by external bodies, but also with regards to associated medical, family and pension benefits. Postdocs in Europe are admittedly better protected than their US colleagues owing to the social policies of European states. But despite these advantages and although some European and US institutes aim to financially match internal and external fellowships, data from the 2009 NSF survey and a 2010 International Salary Survey conducted by Naturejobs indicate that academic postdocs in Europe and the US are underpaid relative to their counterparts in industry. However, the ageing postdoctoral workforce of academia has also meant that increasing numbers of postdocs are raising families and making crucial financial decisions about their future while still in a period of apparent professional hiatus. These demographic shifts in the postdoctoral population call for greater institutional support and professional stability, which remains lacking, particularly in the US.

The need of postdocs to voice and address these concerns has led to the formation in the last decade of postdoctoral and research staff associations across the USA and Europe. The National Postdoctoral Association in the USA, but also broader organizations such as the UK Research Staff Association (UKRSA) and the European Council of Doctoral Candidates and Junior Researchers (EURODOC) aim to support, inform and connect researchers and to protect their interests by advocating administrative and policy changes, and by lobbying institutes and governments to enhance the academic and postdoc experience. Despite important accomplishments of these organizations, postdocs across the US are now seeking more formal representation in the form of postdoc unions. The recently formed University of California postdoc union counts the ratification of a contract increasing salaries, safeguarding employment policies and approving benefits among its successes.

Postdocs drive academic research in many labs. Academic institutions and governments need to respond to these challenges by working with postdoctoral organisations to improve the prospects of $\mathrm{PhD}$ graduates, by adopting more favourable employment and benefit terms and by offering better career structure and opportunities. Normalizing the large disparity in the supply and demand in the academic job market is equally important. To that end, curbing the numbers of $\mathrm{PhD}$ placements and educating current $\mathrm{PhD}$ candidates and postdocs on career paths outside academic research by helping them develop transferrable skills needed in alternative professions (see our December 2010 Editorial) are essential steps. Training mentors to better manage and support the growing postdoc force by striking the right balance between independence and guidance is also key.

Critics of the current system consider it to be an exploitative pyramidal scheme. But even those who argue that academic research is not a profession but a passion conducted for the love of knowledge would admit that the system is antiquated and has failed to respond satisfactorily to pressing issues facing postdocs today. Reconstituting the mutually beneficial relationship between academia and its postdocs is essential to avoid disillusioning future scientists. Concerted efforts of academic institutions, funding bodies, governments and $\mathrm{PhD}$ graduates to improve the postdoc experience will likely benefit all parties involved.

\section{Nature Publishing Group supports the ASCB's childcare awards}

Nature Cell Biology editorials have often highlighted the challenges of balancing the demands of an academic career with family commitments, and emphasized the importance of providing adequate institutional support in the form of progressive policies and relevant infrastructure. We are therefore pleased to announce that Nature Publishing Group will be supporting the American Society for Cell Biology's childcare awards for a period of five years, from 2011-2015. These awards are intended to meet the childcare needs of early-stage researchers who would otherwise find it difficult to participate in the ASCB's annual meeting. 